\title{
EL DERECHO A LA VIDA DIGNA: LUCHAS POR LA VIVIENDA Y VIDA COTIDIANA EN SANTIAGO DE CHILE
}

\author{
THE RIGHT TO A LIFE WITH DIGNITY: HOUSING STRUGGLES AND \\ EVERYDAY LIFE IN SANTIAGO, CHILE
}

\begin{abstract}
Miguel Pérez ${ }^{1}$
En la actualidad, las reflexiones antropológicas sobre las dimensiones éticas de la vida cotidiana han estado crecientemente interesadas en examinar categorías morales como la "dignidad". En ese contexto, gran parte de los trabajos se han ocupado de estudiar los modos en que poblaciones excluidas, a través de sus prácticas ordinarias desplegadas preferentemente en las esferas íntima y privada, buscan alcanzar una vida digna. Este artículo, en contraste, analiza etnográficamente cómo la búsqueda de dignidad en Santiago de Chile, además de tomar la forma de prácticas sociales desarrolladas en el espacio privado, resulta también en formas emergentes de acción colectiva. Para ello, examino las luchas urbanas llevadas a cabo en su mayoría por pobladoras sin casa inscritas en comités de allegados, esto es, en organizaciones sociales reguladas por el Estado a través de los cuales buscan convertirse en propietarias. Explorando específicamente el "derecho a la vida digna" exigido por ellas, sostengo que dicha reivindicación nos ayuda a entender los modos en que los pobres urbanos significan políticamente sus condiciones cotidianas de exclusión, al tiempo que reformulan las demandas estratégicas de sus movilizaciones.
\end{abstract}

Palabras claves: dignidad, luchas por la vivienda, vida cotidiana, categorías morales.

Contemporary anthropological reflections on the ethical dimensions of everyday life have been increasingly interested in examining moral categories such as "dignity". In this context, a large part of these works has been concerned with the study of how excluded populations, through their ordinary practices predominantly in the intimate and private spheres, seek to attain a life with dignity. This article, in contrast, ethnographically analyzes how the pursuit of dignity, in addition to taking the form of social practices performed in the private space, also results in emerging forms of collective action. To do so, I examine the urban struggles carried out in Santiago, Chile, mostly by female urban dwellers in need of housing enrolled in housing committees (comités de allegados), i.e., state-regulated social organizations through which they seek to become homeowners. By specifically exploring the right to a life with dignity demanded by these urban dwellers, I hold that such a claim allows us to understand the ways in which the urban poor make sense of their everyday conditions of exclusion while, at the same time, reformulate the strategic demands of their mobilizations.

Key words: Dignity, housing struggles, everyday life, moral categories.

La antropología contemporánea, particularmente aquella que reflexiona sobre la llamada "ética ordinaria" (Das 2012; Fassin 2012; Lambek 2010a), han volcado su atención al examen etnográfico de categorías morales como la dignidad. Laética ordinaria es una aproximación que sostiene que las prácticas éticas, más que ancladas en una moralidad trascendental, están articuladas a través de palabras, categorías y acciones de la vida cotidiana. Los antropólogos de la ética ordinaria buscan, por tanto, establecer cómo y bajo qué circunstancias los seres humanos actúan moralmente y en qué medida las palabras de uso ordinario les permiten enunciar sus acciones morales. Conceptos como la dignidad, adaptando el trabajo de Michael Lambek (2010b:40), nos ayudarían a reconocer los criterios morales de juicio práctico por el cual las personas hacen "rutinariamente" lo que consideran "bien o mal". La idea de dignidad, siguiendo a Didier Fassin (2012:4), sería entonces una de las "categorías morales" por las que los antropólogos podrían explorar cómo circulan los valores morales, así como los procedimientos éticos -prácticas sobre el yooperando en la formación de sujetos morales. Así, la

\footnotetext{
${ }^{1}$ Departamento de Antropología, Universidad Alberto Hurtado. Almirante Barroso 10, Santiago, Chile. miguelperez@uahurtado.cl
}

Recibido: julio 2018. Aceptado: enero 2019.

http://dx.doi.org/10.4067/S0717-73562019005001304. Publicado en línea: 13-junio-2019. 
pesquisa etnográfica de cómo los individuos configuran prácticas y discursos a través de significantes como la dignidad posibilitaría el reconocimiento de los modos en que éstos se vuelven sujetos morales.

En una provocadora crítica a la ética ordinaria, Zigon señala que categorías como la dignidad tienen un valor antropológico no porque nos permitan examinar cómo "la gente que estudiamos actúa bien o mal" (Zigon 2014:751), sino porque son conceptos morales familiares que apuntan "un problema o imperativo ético... que motiva acciones en el mundo" (Zigon 2014:762). En su opinión, la dignidad es menos el fin de las acciones morales que un indicador que nos deja saber dónde ubicar los dilemas éticos; disyuntivas que emergen en lo que él denomina "colapsos morales" (Zigon 2007, 2014; ver adelante). En este artículo, adapto la perspectiva de Zigon para afirmar que la categoría dignidad no solo opera como un indicador de dilemas éticos, sino también como un significante político por el que grupos excluidos pueden desarrollar nuevas formas de movilización política. Las protestas por el derecho a la vida digna en Santiago de Chile llevadas a cabo por los allegados término empleado en la política pública chilena para referir a las familias sin casa que comparten una vivienda con familiares puede entregar importantes luces al respecto.

¿Por qué estudiar las demandas públicas por dignidad entre los pobres urbanos? Antropólogos y etnógrafos de otras disciplinas que han indagado en cómo los individuos buscan alcanzar una vida digna se han enfocado preferentemente en las acciones de resistencia y/o resignificación que, en su vida íntima o privada, éstos llevan a cabo (Cleaveland 2005; Han 2012; Pauli 2008). Aunque con algunas excepciones (Auyero 2003; Fisher 2018), la gran mayoría de los trabajos entienden la conquista de dignidad y reconocimiento social como una empresa personal más que colectiva. En el caso de Chile, Han (2012) afirma que la conceptualización de la dignidad de los pobladores (pobres urbanos) comprende una serie de prácticas de solidaridad y reciprocidad desarrolladas en la esfera doméstica, las que van desde pedir alimentos en casos de necesidad extrema o solicitar el cuidado de hijos e hijas a vecinas. En palabras de Han, el vivir con dignidad "no es formalizado ni públicamente pronunciado... sus contornos, más bien, emergen a través de un compromiso sostenido con la vida cotidiana en la población" (Han 2012:69). Así, a través de esas prácticas de solidaridad, los residentes populares responderían a momentos críticos tales como la pérdida de un ser querido, la cesantía o la incapacidad de administrar una crisis económica.

Mediante el análisis las luchas por la vivienda en el Chile neoliberal, en este artículo sostengo que la búsqueda de dignidad, además de asumir la forma de prácticas sociales desplegadas en la esfera privada, permite también la formulación de reivindicaciones públicamente expresadas, así como la reconfiguración de las demandas estratégicas del movimiento por la vivienda. Otros antropólogos han observado procesos similares tanto en Chile (Murphy 2015) como en otros países de América Latina (Caldeira 2017; Holston 2008). No obstante, dichos análisis se han concentrado preponderantemente en los procesos de autoconstrucción por los que familias sin vivienda han erigido sus espacios residenciales. El caso que aquí examinaré difiere en un aspecto fundamental: los pobladores chilenos conquistan la vivienda ya no a través de ocupaciones de terreno ni de autoconstrucción, sino que mediante su participación en programas neoliberales de asignación de subsidios (Angelcos y Pérez 2017; Pérez 2017b; Sungranyes 2005). En ese sentido, me gustaría interrogar en qué medida las aspiraciones de los allegados por convertirse en propietarios, deseo concretado en su involucramiento en políticas neoliberales de vivienda, configuran sus reclamos por dignidad.

Mucho se ha dicho sobre los efectos desmovilizadores de las políticas neoliberales en la subjetividad de los pobres urbanos chilenos, así como sobre su capacidad para resistir una gubernamentalidad neoliberal (p.ej., Han 2012; Murphy 2015; Özler 2012; Paley 2001; Schild 2000). Mi interés, no obstante, no está en determinar si la participación de los pobres en programas de subsidios resulta en la conformación de subjetividades neoliberales o no. Más bien, me ocuparé de reflexionar sobre cómo pobladores y, principalmente, pobladoras discuten las formas en que son construidos como sujetos de políticas públicas mediante reivindicaciones políticas por el derecho a la vida digna (Figura 1). En particular, problematizaré dos aspectos que mis interlocutores percibían como expresiones de un sistema que humilla y degrada a los pobres: primero, sus condiciones de allegamiento, hecho resultante de la falta de viviendas sociales en su barrio de origen; segundo, las formas en que la Ficha de Protección Social -el instrumento de caracterización del Estado para focalizar beneficios sociales ${ }^{1}$ - los construía como vulnerables. Sostengo que vivir de allegados y ser reconocido como vulnerables provoca la aparición de una serie de eventos cotidianos que estos sujetos entienden como "dilemas éticos" (Zigon 2007, 2014); dilemas que amenazan su subjetividad como pobres dignificados. Afirmo que es solo cuando los y las allegados/as lidian colectivamente con esos dilemas cuando el concepto de vida digna puede ser imaginado como el "horizonte político" (Movimiento de Pobladores en Lucha 2011:16) de las movilizaciones por la vivienda del Chile neoliberal. 


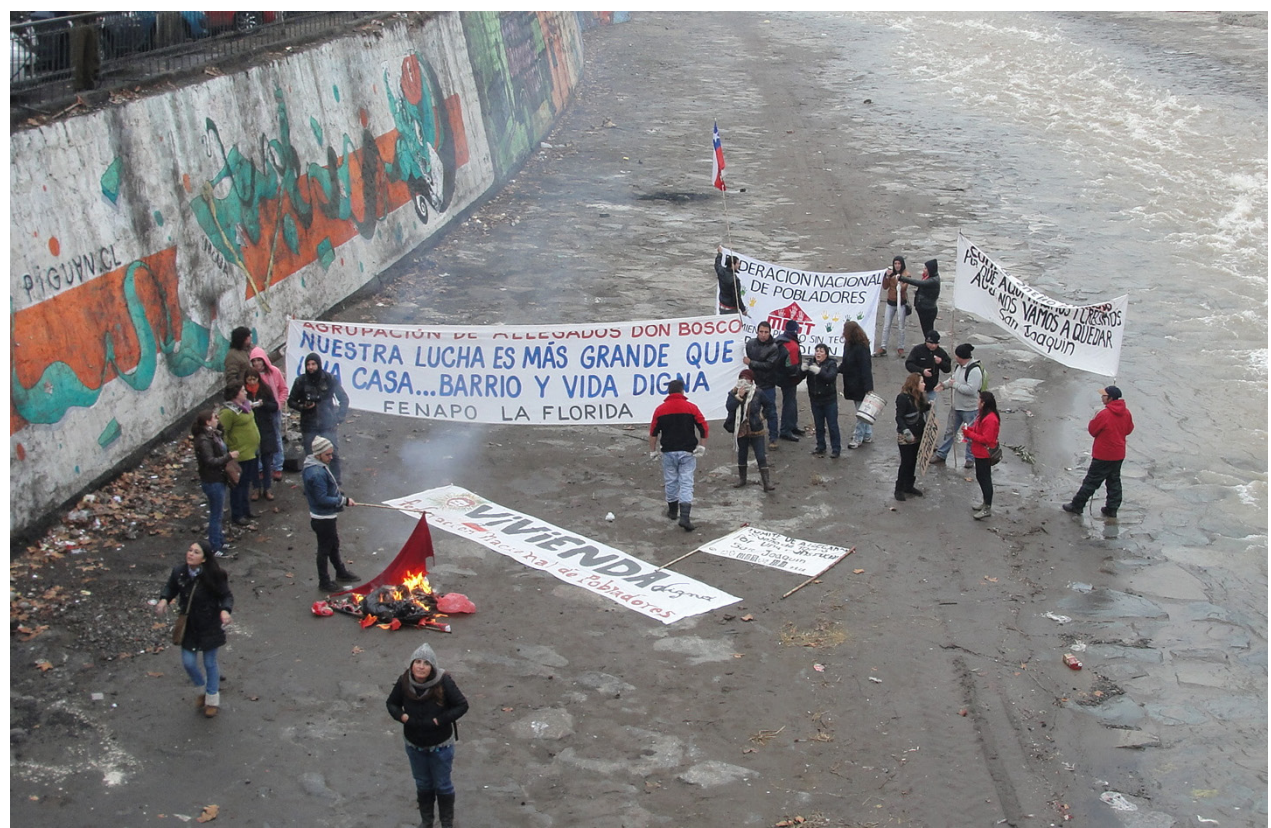

Figura 1. Manifestación de la Federación Nacional de Pobladores (FENAPO) en el lecho del Río Mapocho en Santiago. Uno de los lienzos que porta el Comité de Allegados don Bosco reza: "Nuestra lucha es más grande que una casa... Barrio y vida digna". Junio de 2014. Foto del autor.

The National Federation of Poor Residents (FENAPO) protesting on the Río Mapocho riverbank. One of the banners the Don Bosco Housing Committee carries reads: "Our struggle is larger than a house... Neighborhood and life with dignity". June 2014. Photo by the author.

\section{Materiales y Métodos}

El material que aquí discuto proviene de un trabajo de campo etnográfico de 15 meses llevado a cabo en Santiago entre 2013 y 2015. Dicho estudio comprendió la realización de más de 60 entrevistas en profundidad a allegados de Santiago ${ }^{2}$, a través de las cuales se buscó conocer sus motivaciones para luchar por la casa propia, así como las expectativas asociadas a su trasformación en propietarios. Igualmente, realicé observación participante durante los meses de trabajo de campo en un "comité de allegados", esto es, en una asamblea de vivienda regulada por el Estado a través de la cual los pobres postulan a subsidios habitacionales para alcanzar la vivienda en propiedad. Dicha técnica me permitió caracterizar cómo la idea de vida digna se traducía en prácticas políticas concretas, las que incluían asambleas vecinales, reuniones con autoridades ministeriales y protestas públicas. En particular, este artículo presenta los hallazgos de mi involucramiento en el Comité de Allegados Don Bosco, organización formada en 2002 en la Población Nuevo Amanecer de la comuna de La Florida. Trece años después de su fundación, hacia 2015 , este comité contaba con más de setecientos postulantes, en su mayoría mujeres, quienes aún estaban a la expectativa de convertirse en propietarias. La lucha de estas allegadas, fenómeno marcado por una espera prolongada por alcanzar una casa propia, será el centro de mi análisis. En el caso estudiado, al contrario de lo descrito por Auyero (2012), el acto de espera no operaba solo como uno de los instrumentos de gobierno mediante las cuales los pobres se sujetan al poder estatal. Aunque frustrante y a veces desalentadora, la experiencia de espera, no cumplía un rol puramente disciplinario, puesto que funcionaba como catalizador de una respuesta política y organizada frente a un Estado que, en palabras de las allegadas, no garantizaba una vida digna. Para dar cuenta de cómo ellas se movilizaban para conquistar sus deseos por una vida digna, partiré caracterizando la estrecha relación entre la lucha por la vivienda y las demandas por dignidad. Luego de ello, describiré cómo estas pobladoras significaban su experiencia como allegados/as para, de este modo, comprender los sentidos desplegados en su protesta.

\section{Luchas por la vida digna en Santiago}

En Chile, el concepto dignidad ha sido una parte fundamental del lenguaje político empleado por los 
pobladores, quienes han hecho uso de esta categoría para concebirse a sí mismos como sujetos de derechos y para imaginar el tipo de vida futura al que aspiran. Sin embargo, las demandas por dignidad han cambiado de manera importante en el tiempo. A mediados del siglo XX, cuando casi medio millón de habitantes vivía en asentamientos informales en Santiago (las llamadas "poblaciones callampas"; Santa María 1973), las reivindicaciones por dignidad respondían principalmente a unas condiciones de vida caracterizadas como "irregulares e insalubres" (Murphy 2015:83). La Iglesia Católica, en este contexto, jugó un rol crucial tanto en denunciar las condiciones residenciales de estos habitantes como en articular un lenguaje moral en el cual los pobres podían reconocerse a sí mismos como individuos dignificados. La Revista Mensaje, el medio de difusión de los Jesuitas, fue una de las plataformas principales en que se transmitió el mensaje de dignidad humana y salvación promovido por la Iglesia Católica. Allí, en 1957 el sacerdote Hurtado Echeverría (1957:461) afirmaba que vivir en "rancheríos indignos de seres humanos" podría llevar al "desquiciamiento moral y cívico" de los pobres. Los llamados curas obreros -muchos de los cuales eran, en efecto, Jesuitaseran los misioneros que, involucrados activamente en la formalización de los asentamientos irregulares, podrían salvar a los pobladores de convertirse en residentes indignos, marginados e inmorales.

Esta visión de la dignidad como dependiente de la actividad misionera de la Iglesia Católica fue prontamente cuestionada por los pobladores, especialmente una vez que estos radicalizaron sus movilizaciones. Entre mediados de 1960 y 1973, la politización creciente de los pobres urbanos y la emergencia de protestas masivas por la vivienda -el llamado "movimiento de pobladores (Angelcos y Pérez 2017; Castells 1973; Murphy 2015)- transformó las formas de concebir los asentamientos irregulares. $\mathrm{La}$ ocupación de terrenos y el acto de residirinformalmente en las periferias urbanas ya no fue entendido como sinónimo de un tipo de habitación inmoral e indigno, sino como expresión de las capacidades agenciales de los pobres. Constituidos como sujetos políticos a través de su involucramiento en las prácticas de autoconstrucción de ciudad (Angelcos y Pérez 2017), los pobladores comenzaron a ser reconocidos como actores colectivos capaces de transformar la sociedad. En este marco, la dignidad defendida por los pobres sin casa nacía de su condición de sujetos revolucionarios, lo cual los convirtió en una de las principales fuerzas apoyando el proyecto socialista de Salvador Allende (1970-1973).

La dictadura de Augusto Pinochet (1973-1990), luego de derrocar el gobierno de Allende, tuvo un profundo impacto en el modo en que los pobladores comenzaron a concebir la dignidad. Por un lado, el régimen de Pinochet reprimió severamente las ocupaciones de terreno, erradicó masivamente a sus residentes y asesinó a cientos de pobladores (Murphy 2015). Por otro lado, implementó un modelo de desarrollo urbano inspirado en principios neoliberales que, quitando las regulaciones al suelo urbano, abrió la ciudad al mercado. Las movilizaciones sociales sufrieron un repliegue importante y los pobres fueron incapaces de obtener vivienda a través de la toma de predios urbanos. Ya que la vida misma de los pobladores estaba en riesgo, las demandas por dignidad tomaron la forma de reclamos por el derecho a vivir en libertad y democracia. Ello explica la emergencia, en muchos casos apoyadas por la Iglesia Católica, de estrategias comunitarias de supervivencia ${ }^{3}$ como las ollas comunes, una forma de comedores populares. Al mismo tiempo, quienes aspiraban a convertirse en propietarios comenzaron a participar en nuevos programas de vivienda basada en la asignación de subsidios, los que fueron parte del plan de modernización implementado por el régimen desde finales de la década de 1970. Consistente con la orientación neoliberal de estas reformas, los programas de vivienda entendían a los pobladores como actores racionales quienes podrían alcanzar la vivienda en propiedad mediante ahorros privados y subsidios estatales (Pérez 2017b).

El carácter neoliberal de las políticas urbanas se mantuvo luego del retorno a la democracia en 1990. Los gobiernos posteriores a la dictadura, en efecto, han hecho poco por alterar la racionalidad de mercado en que se funda el modelo de desarrollo urbano imperante (Özler 2012). El Estado de Chile aún concibe la vivienda social como una mercancía que los grupos populares pueden alcanzar con ahorros privados y subsidios públicos. Este modelo de producción de viviendas, sin embargo, ha sido sumamente exitoso en la construcción de soluciones habitacionales. Especialmente durante los noventa, el Estado de Chile construyó una cantidad sin precedentes de unidades residenciales, reduciendo el déficit de vivienda de 918.756 en 1990 a 743.450 en 2000 (Pérez 2017b).

La expansión cuantitativa de la vivienda social subsidiada, sin embargo, no ha traído mejores condiciones de vida para los sectores populares. Para obtener la casa propia, los pobladores han sido sistemáticamente expulsados de sus barrios de origen siendo relocalizados en la periferia segregada de Santiago (Castillo y Forray 2014; Tapia 2011). Ello ha llevado a la reemergencia del movimiento por la vivienda en la última década, manifestada en la aparición creciente de comités de allegados a través de los cuales, haciendo un uso estratégico de las políticas de subsidios, los pobladores buscan obtener vivienda en sus barrios de origen (Angelcos y Pérez 
2017; Pérez 2017a, 2017b). Las reivindicaciones contemporáneas por la dignidad, en este contexto, ya no surgen como reacción a condiciones de vida propias de "rancheríos indignos", parafraseando al sacerdote Hurtado Echeverría. Más bien, estas afloran como respuesta a políticas neoliberales que, además de segregar a los pobres, conciben la vivienda como una mercancía distribuida bajo el principio de focalización; esto es, bajo la idea de que solo pueden acceder a ella quienes son categorizados como "vulnerables" por los instrumentos de caracterización socioeconómicas del Estado. ¿De qué manera viven los "vulnerables" y cómo su existencia cotidiana en tanto allegados conforma sus reclamos políticos por dignidad?

\section{La movilización de las allegadas}

Cuando comencé mi trabajo de campo en el Comité de Allegados Don Bosco en agosto de 2013, noté de inmediato una presencia abrumadora de mujeres. Como pude comprobar posteriormente, el libro de socios del comité precisaba que $86,6 \%$ de los 880 individuos alguna vez registrados eran mujeres. Diversos autores ya han enfatizado en carácter predominantemente femenino de las movilizaciones urbanas (Caldeira 2015; Murphy 2015; Paley 2001). En el caso particular del Don Bosco, me llamaba la atención tanto el número como las formas en que las mujeres se involucraban con la organización. Ellas no solo participaban más activamente que los hombres en marchas y protestas públicas, sino que también asumían mayores posiciones administrativas y de liderazgo.

Ángela era una de las mujeres que tenía a su cargo tareas como recolectar los pagos mensuales y tomar notas en las reuniones sostenidas en el Servicio de Vivienda y Urbanismo (SERVIU), entidad encargada de la asignación de subsidios. Ella, una allegada que rozaba los cincuenta años, no tenía una ocupación formal, pero ocasionalmente trabaja en ferias libres vendiendo ropa y otros artículos de hogar. A los seis años, llegó a vivir al Campamento Nueva La Habana, un asentamiento autoconstruido fundado por el Movimiento de Izquierda Revolucionaria en 1970 que, posterior al golpe militar, pasó a llamarse Población Nuevo Amanecer. Ángela se unió al Comité Don Bosco en 2009, después de vivir como allegada en la casa de su suegra por casi veinte años. "Antes de eso", me dijo, "solo estaba en la casa".

En mis conversaciones con otras allegadas, pude escuchar historias similares. ¿Qué -me pregunté- lleva a una mujer con poca experiencia organizativa a "dejar de estar en la casa", unirse a un comité de allegados y asumir un rol activo en la lucha por la vivienda? Con esa inquietud en mente, después de muchos intentos fallidos, en enero de 2014 visité a Ángela en su casa, una precaria vivienda de madera construida en el patio trasero de la casa de su suegra. Pasado unos minutos después de mi arribo, simplemente le pregunté: “¿qué te motivó a entrar en el comité?" Su respuesta no fue tan sugerente como la forma en que la articuló. "Mi vivienda... entré al comité porque quiero tener mi casa propia", dijo mirando por la ventana, como no queriendo ser oída desde el patio. Luego, en voz baja agregó: "es muy difícil vivir de allegada".

Ángela vivía en la casa de la madre de José, su pareja, desde 1990. Esta casa era como muchas otras de la Población Nuevo Amanecer: de ladrillo, pareada y de un piso construida sobre una propiedad residencial de unos 150 metros cuadrados. En un comienzo, Ángela vivió dentro de la casa de su suegra, sin embargo, los problemas pronto aparecieron; otros trabajos etnográficos en América Latina han demostrado que, cuando nueras y suegras comparten el espacio residencial, las relaciones mediadas por la violencia son comunes (Pauli 2008). Residencia virilocal, descendencia patrilineal y patriarcado extendido, señala Pauli (2008), enmarcan la ocurrencia de esos hechos. En el caso de Ángela, ella narraba esos eventos de esta forma:

Al comienzo, vivir con mi suegra fue un desastre [...] Dos mujeres no pueden vivir juntas porque las dos quieren ser dueñas de casa, las dos quieren mandar [...] No nos llevábamos [con mi suegra] bien e incluso llegamos a pegarnos, así que decidimos construir esto [su vivienda] acá en el patio.

La familia de Ángela y José eran parte del 19,4\% de familias chilenas que, para el 2014, no contaban una vivienda propia (Ministerio de Desarrollo Social 2014). En el caso de Ángela, la disponibilidad de espacio dentro de la propiedad de su suegra permitió la construcción de una vivienda separada, cuestión que resolvió en parte la violencia doméstica en que se vio envuelta. No obstante, la tensión todavía persistía en 2014. Ahora, los problemas derivaban del hecho de que Ángela sentía la obligación de demostrar la independencia económica de su núcleo familiar. Para ella, el hecho de ser una mujer adulta sin una casa propia la forzaba a legitimar sus demandas por vivienda mediante la afirmación de su autosuficiencia. Durante los meses que pasé con Ángela, pude notar la significación de actividades como estar al día en el pago de las cuentas o mantener su casa perfectamente limpia. A través de esas acciones, Ángela reconocía que su condición de allegamiento, aunque precaria, no constituía una vida sin dignidad.

En muchos otros casos pude atestiguar cómo las allegadas legitimaban sus demandas por vivienda mediante la autoidentificación como sujetos económicamente independientes capaces de 
autogobernarse. No obstante, todas ellas se enfrentaban a una realidad donde su capacidad de acción parecía mucho más limitada: la imposibilidad de organizar su vida doméstica según sus propios criterios de privacidad; esto es, la incapacidad de establecer autónomamente reglas básicas de coexistencia. Natalia, una miembro del Don Bosco que vivía en una pieza con su pareja y dos hijos en la casa de su suegra, afirmaba "el aspecto más negativo de vivir de allegado es la poca privacidad". "Vivir de allegada no se lo deseo a nadie", me dijo Andrea, otra postulante del comité, agregando que "puede ser la mamá, o la tía, quien sea, pero siempre están recalcando de que la casa es de ellos, siempre". Para Natalia y Andrea, así como para mis otras interlocutoras, resultaba ciertamente incómodo llevar a cabo actividades diarias como compartir un baño entre seis, siete o más personas; o tener que agendar días específicos para usar una lavadora entre dos o tres familias. Sin embargo, parecía mucho más exasperante no tener voz en cómo se organizaba la vida doméstica dentro de la propiedad residencial en que vivían. Al respecto, en un acto de sinceridad, Ángela me comentó la incomodad que, en un comienzo, sentía por mi presencia en su casa pues eso implicó tener que “dar explicaciones" a su suegra. Luego de ello, señaló: "nunca invito gente a mi casa porque si alguien viene tiene que pasar por la cocina [de la casa principal] y mi suegra, que es muy conservadora, me va a hacer muchas preguntas... [como allegada] tú estás dando explicaciones todo el tiempo".

Para las allegadas, la imposibilidad de disponer libremente de los espacios residenciales se materializaba en momentos específicos como el hecho de "pedir permiso" o "dar explicaciones". En esos momentos, ellas se veían a sí mismas obligadas a subordinar su subjetividad a las reglas del propietario o propietaria de la vivienda. En ese sentido, el modo de habitar propio del allegamiento era entendido como estructurado por relaciones cotidianas de subyugación que comprometían su dignidad personal. Tener una casa propia emergía, entonces, como una precondición para alcanzar una vida digna. Para Rosa, una de las fundadoras del Comité de Allegados Don Bosco, una vivienda digna era aquélla en donde "yo tenga mi living comedor, mi cocina, mi baño, [y] dormitorio para mis hijos". Es decir, ella imaginaba una vida digna como propietaria a través de espacio doméstico que se ajustara a criterios de privacidad que ella, autónomamente, pudiera definir. ¿Por qué? Porque, al igual que para otras allegadas, el anhelo de la casa propia representaba la única posibilidad de subvertir un dominio privado que no solo limitaba su privacidad, sino que restringía su capacidad para actuar soberanamente en el hogar.

\section{Pobreza y vulnerabilidad en el Chile neoliberal: dilemas y resistencias}

El concepto de vida digna de las allegadas, sin embargo, no se sustenta solo en una evaluación de sus condiciones residenciales. Sus ideas de la dignidad también nacen a partir de un juicio crítico de las formas en que los instrumentos de caracterización social del Estado -específicamente la Ficha de Protección Social- los construían como sujetos vulnerables ${ }^{4}$, condición fundamental para la postulación a subsidios de vivienda. Inspirada en la noción foucaultiana de gubernamentalidad, algunos autores sostienen que en las sociedades neoliberales los programas sociales funcionan como tecnologías de gobierno que transforman a los individuos en sujetos-ciudadanos autosuficientes y autogobernados mediante procedimiento de medición y cuantificación de su elegibilidad (Cruikshank 1999; Ong 2003). Desde esta perspectiva, los programas de asistencia buscan infundir una racionalidad política específica en aquellos que poseen ciertos criterios de elegibilidad, de modo que sean capaces de conducir autónoma y libremente su conducta (Ong 2003; Rose 1999). Si, como en el caso de las allegadas, un individuo es elegible para subsidios no lo es por su condición de ciudadano, diría Cruikshank (1999), sino que por una serie de operaciones calculativas que lo definen y forman como vulnerable.

Esta perspectiva de análisis nos invita a considerar una consecuencia no menor: las allegadas-beneficiarias no solo deben sujetar su vida cotidiana al escrutinio de agencias estatales, sino que además deben comportarse "apropiadamente"; esto es, de acuerdo a los criterios de elegibilidad que los hicieron beneficiarios (p.ej., ahorrando dinero solo para la libreta de ahorro de vivienda y no para otros fines). Para mis interlocutoras, saberse vigiladas por agencias estatales resultaba profundamente perturbador. De ahí, por ejemplo, que muchos allegados del Don Bosco evitaran mostrar sus vehículos particulares en las asambleas del comité por miedo a ser "descubiertos" por funcionarios estatales del SERVIU. Todo aquello revela un punto central que me gustaría enfatizar: la identificación subjetiva de los allegados como pobres y trabajadores choca con las representaciones de la pobreza en la que se inspiran los programas estatales. Ello explica que gran parte de la crítica de los pobladores se dirigiera contra la Ficha de Protección Social.

En términos simples, la Ficha de Protección Social -llamada popularmente "la Ficha"- era una encuesta usada por el Estado para seleccionar a las familias beneficiarias de programas sociales. En América Latina, este paradigma de distribución de beneficios ha sido 
conocido como focalización, política que ha llevado a la creación de programas que, en contraste con el principio de universalidad, están orientados solo a los segmentos más pobres de la población (Candia 1998). En Chile, quienes desean ser propietarios de una vivienda subsidiada debían ser clasificados como vulnerables por esta encuesta. Para ello, eran entrevistados por un agente del Estado, generalmente un asistente social de la municipalidad en donde residían. Algunas semanas más tarde, sobre la base de las respuestas a la encuesta, se les asignaba un puntaje que era calculado por el Ministerio de Desarrollo Social. Este puntaje era usado para colocar a los futuros propietarios en un quintil, el que determinaba a qué programa podían postular ${ }^{5}$. La mayoría de los miembros del Comité de Allegados Don Bosco se ubicaban en el primer quintil, lo que significaba que esta asamblea recibía subsidios desde el Fondo Solidario de Elección de Vivienda, programa destinado a las familias más pobres del país.

La Ficha de Protección Social fue diseñada por el primer gobierno de Michelle Bachelet (2006-2010) como una parte integral de su Sistema de Protección Social. En tanto innovación propia de los estados de bienestar del neoliberalismo (Ferguson 2015), los programas de protección social de Bachelet buscaron distribuir el gasto social entre las familias de clase baja y media baja que no hayan sido capaces de consolidarse económicamente. En contraste con sus predecesoras -las Fichas CAS y CAS II, que distinguían entre pobres y no-pobres sobre la base de la posesión de bienes materiales (ver más en Han 2012; Schild 2000)- "la Ficha" buscaba abordar el carácter dinámico de la pobreza del Chile neoliberal. Esto implicaba que, en este instrumento, una familia primeramente clasificada como no vulnerable podía perfectamente ser recategorizada como vulnerable si su situación económica se veía modificada. Para ello, la Ficha de Protección Social, aparte de las mediciones sobre el tipo de vivienda, el ingreso familiar, nivel educacional del dueño de hogar y el acceso a servicios básicos, incluía otras variables como la capacidad potencial de un individuo de generar ingresos (Larrañaga et al. 2014).

En 2011, el presidente Sebastián Piñera propuso cambiar la Ficha de Protección Social para develar lo que el exministro de Desarrollo Social Joaquín Lavín llamó "falsos pobres" (El Mercurio 2011); a saber, todos aquellos que, al momento de ser encuestados, habrían mentido para ganar acceso a beneficios sociales. La Federación Nacional de Pobladores (FENAPO) reaccionó vehementemente a los cambios, aduciendo que dicha iniciativa solo exacerbaría la focalización de recursos al impedir que muchas familias pobres resultaran elegibles para subsidios. En una movilización nacional el 13 de diciembre de 2011, la FENAPO lanzó el siguiente comunicado:

Rechazamos la Ficha de Protección Social como un mecanismo válido de medición, ya que su diseño lo que busca es falsear la realidad para esconder la pobreza en Chile, calificando como no-pobres a miles de familias que viven en una precaria situación [...] Denunciamos y responsabilizamos al Ministerio de Desarrollo Social...de querer acabar con la pobreza por decreto [...] Usando la excusa de que los pobres mentimos, el gobierno quiere meterse en nuestros datos personales y privados, lo que rechazamos absolutamente por constituir un atentado en contra de nuestra privacidad y una discriminación hacia los pobladores, pues en este país a la clase alta no se le aplica ninguna encuesta y nadie se mete en sus casas para medirlos (FENAPO, Declaración Pública, 13 de diciembre de 2011).

Esta declaración la entiendo no solo como un cuestionamiento a las formas en que el Estado se ocupa de la producción de conocimiento científico sobre la pobreza, sino también como una crítica profunda, en un sentido foucaultiano, al carácter objetivizante de la Ficha de Protección Social. En específico, los activistas criticaban el carácter clasista de este instrumento: son solo los residentes pobres, decían ellos, quienes son medidos, evaluados y clasificados por las tecnologías de categorización del Estado. Por lo mismo, se cuestionaba la idea casi naturalizada de que son los pobres los únicos ciudadanos sujetos a un escrutinio moralizador de cómo viven o qué hacen en su vida privada. Dicho aspecto se conjuga con otro elemento no menor: a pesar de que todos mis informantes tenían certezas de qué era la Ficha y cuál era su función en la distribución de beneficios sociales, nadie tenía muy claro cómo operaba ésta ni menos los procedimientos o cálculos que determinaban la clasificación de los niveles de vulnerabilidad. Para ellos, la Ficha de Protección Social funcionaba como una caja negra que definía discrecionalmente los niveles de vulnerabilidad de las familias. En su visión, no había nada objetivo en el cálculo de los puntajes, idea sustentada en su conocimiento empírico: todos y todas decían conocer amigos, familiares o vecinos que, a pesar de tener condiciones de vida similares, recibían puntajes muy distintos. Dicha opinión estaba directamente asociada a un sentido de incertidumbre ampliamente extendido: "tú nunca sabrás -me dijo un allegado- qué puntaje vas a tener". 
En este contexto de incerteza generalizada, mentir durante la aplicación de la encuesta era una estrategia común para obtener bajos puntajes. El acto de mentir, si bien no era públicamente reconocido, tampoco era un tabú entre los miembros del Don Bosco. La sinceridad de Carla, en este sentido, me sorprendió. Madre de un niño de cuatro años e hija de una trabajadora doméstica, Carla fue una de las pocas personas que conocí que había estudiado en la universidad. Trabajaba como maestra de educación preescolar, pero su salario -cerca de US\$615 mensuales- no le permitía obtener una vivienda en el mercado privado. Postular al subsidio para grupos vulnerables era, entonces, la única posibilidad de convertirse en propietaria. Sin embargo, Carla tuvo dificultades para ser reconocida como elegible antes de ingresar al Comité de Allegados Don Bosco:

A mí me costó entrar al comité, porque por decir que yo tenía una carrera universitaria ya me daban nueve mil quinientos puntos $[\ldots]$ Por eso [las personas] mienten mucho en La Ficha; uno tiene que mentir. En mi caso, fui [a la municipalidad] a hablar con la asistente social y fui súper pesada para que me bajaran el puntaje, porque le dije ¿qué quiere? ¿que no me lave la cara una semana, que no me bañe una semana, que venga con el pelo sucio, le mienta que no estudié, que no trabajo? De ahí, tránsfugamente yo creo, al otro día me vino a ver una asistente y me dijo que tenía dos mil quinientos puntos".

Mentir era un modo de acción importante usado por los allegados para lidiar con la ansiedad que provocaba el sentido de incertidumbre, así como para resistir las formas en que el Estado medía, clasificaba y representaba a los pobres. Para Carla, tener un título profesional resultaba profundamente problemático ya que podría ser indicador de su condición no vulnerable. Carla veía cualquier mejora material en su vida como un riesgo inminente de ser excluida de los programas de subsidios, paradoja que la hacía articular sus reclamos contra la Ficha como un asunto de dignidad. En su discusión con la asistente social de la municipalidad, el argumento "¿qué quiere? ¿que no me lave la cara una semana" denota que, para ella, la forma fácil de acceder a beneficios era renunciar a su dignidad. ¿Cómo? Asumiendo el papel de una mujer desaseada y andrajosa. Sin embargo, no estaba dispuesta a hacerlo. Carla escogió "reclamar" personalmente para que le bajaran el puntaje. Pero, al mismo tiempo, no condenaba moralmente a quienes mentían; más aún, los justificaba. "Uno tiene que mentir", afirmaba.

La historia de Carla retrata una disyuntiva central que enmarcaba la participación de los allegados en los programas de vivienda: sus deseos de prosperar en la vida chocaban con lo que el Estado y una sociedad de clases esperan de ellos como sujetos viviendo en la pobreza. El reconocimiento de los pobres como beneficiarios de subsidios, de este modo, provocaba una consecuencia inquietante para mis informantes: dicho reconocimiento, para ellos, encarnaba tanto una representación banal de sus condiciones de vida, como también una amenaza a su subjetividad como pobladores dignos. Es en este contexto en que el derecho a la vida digna emergía como una nueva orientación estratégica de las movilizaciones por la vivienda en Chile.

\section{La dignidad como derecho}

El Movimiento de Pobladores en Lucha -MPL, una organización política afiliada a la FENAPO- publicó, en 2011, un libro que contiene sugerentes reflexiones sobre el carácter de las actuales movilizaciones por la vivienda. En uno de sus pasajes, se afirma que la vivienda es solo el comienzo de una lucha permanente, la lucha por la vida digna. La vida digna, en este marco, se entiende como el nuevo horizonte político del movimiento:

[...] la casa es solo el principio de una larga y permanente lucha, la lucha por la Vida Digna. Es una opción de libertad que no se pide, sino que se conquista en el día a día. Representa un sendero amplio que abarca distintas dimensiones del vivir y de poblar un territorio, como la vivienda, pero también la salud, la educación, el trabajo, nuestra identidad... [la Vida Digna] no representa un ideal externo, sino un horizonte construido desde la propia gente, de sus sueños, deseos y anhelos de vivir bien (Movimiento de Pobladores en Lucha 2011:31, énfasis agregado).

A simple vista, la vida digna reivindicada por los pobladores emerge de una concepción de la dignidad como intrínseca al acto de luchar. En ese sentido, no es externa a los individuos, sino el resultado de una serie de prácticas transformadoras de la vida cotidiana. ¿Qué implica, no obstante, tener un horizonte político anclado en una categoría moral como el concepto de dignidad? Zigon (2014) relaciona el concepto de dignidad al de habitar argumentado que las demandas políticas por dignidad emergen del "colapso moral" (moral breakdown) experimentado por quienes han sido forzados a vivir una cotidianeidad que se torna invivible; una cotidianeidad que, en palabras de Zigon, es "similar a estar atrapados en el mundo" (2014:756-757). Zigon define los colapsos morales como momentos de dilemas éticos en donde las expectativas y disposiciones morales que se tienen a mano son insuficientes para llevar a cabo 
la vida cotidiana. En esos momentos, los individuos se ven obligados a desarrollar tácticas reflexivas para superar esos dilemas éticos, siendo la reivindicación por derechos a la dignidad una expresión consolidada de aquello.

Las experiencias de las allegadas que he descrito pueden ser pensadas, entonces, como estructuradas por un conjunto de colapsos morales. En particular, describí dos de estos colapsos en los cuales su subjetividad como pobladoras dignificadas se encuentra tensionada: primero, los eventos que organizan su vida como allegadas, materializados en acciones en que deben pedir permiso o dar explicaciones sobre su vida privada; y segundo, los momentos en que se ven enfrentadas a la necesidad de tener un puntaje lo suficientemente bajo como para poder optar a subsidios. Mientras en el primer caso las allegadas se ven compelidas a subordinar su agencia individual a, como en el caso de Ángela, las reglas de su suegra para así evitar violencia doméstica, en el segundo se ven forzadas a representarse a sí mismas como indignas para ser calificadas como vulnerables. Confrontadas a esos dilemas, las allegadas desplegaban tácticas reflexivas como integrar una asamblea de vivienda, postular colectivamente por subsidios o, derechamente, mentir en la Ficha de Protección Social.

Son precisamente estas tácticas las que hacían posible la formulación de un lenguaje político basado en la dignidad por el que nuevas generaciones de pobres urbanos resistían al carácter exclusionario de las políticas de vivienda neoliberal. El acto de superar esos dilemas éticos, por tanto, sentaba las bases para que el derecho a la vida digna emergiera como la nueva demanda estratégica del movimiento por la vivienda. ¿Qué, sin embargo, entendían por "vida digna" mis interlocutoras? En términos generales, ellas formulaban sus respuestas a dicha interrogante mediante conceptos como la seguridad, el bienestar y la justicia. La "vida digna", en un sentido amplio, operaba de este modo como un referente general para designar lo que Margalit (1996:1) llama una "sociedad decente", a saber, una sociedad "cuyas instituciones no humillan a las personas", lo que se traduce en demandas concretas por condiciones materiales mínimas. Rosa, por ejemplo, articulaba sus ideas sobre la vida digna de esta forma: "Una vida digna se consigue en un barrio que tenga comodidades en cuanto a todos los servicios que necesitas, una buena locomoción, un buen consultorio, una buena plaza donde salir, juegos para los niños, vivir sin delincuencia".

Ante la pregunta sobre qué constituye una vida digna, la respuesta de Laura -una allegada de comuna de La Pintana a quien conocí a través de la FENAPO- fue, sin embargo, particularmente reveladora. A la demanda por infraestructura pública, Laura sumaba el carácter agencial de los pobladores:

La vida digna es la que nosotros queramos, la que uno mismo dibuja [...sin importar] si queremos casas cuadradas, redondas, chicas; $\mathrm{si}$ las construimos todas juntas, todas separadas, todas pegadas; o si tenemos el parque al medio, en la esquina [...] la vida digna la construimos nosotros con los derechos que el Estado debiese garantizarnos.

La definición de vida digna de Laura, de manera similar a la del Movimiento de Pobladores en Lucha y a la de Rosa, se sustentaba en la identificación de dos dimensiones interrelacionadas. La primera refiere a los aspectos materiales de la vida en la ciudad. Una vida digna, en su visión, era primeramente aquella en donde los componentes materiales del espacio urbano -casas, plazas, parques, etc.- se construyen en función de los intereses y necesidades de los habitantes populares. La segunda dimensión alude a los modos de participación política que hacen posible la conquista de las condiciones materiales mínimas para una vida digna. En ese sentido, Laura concebía la vida digna como resultado de una lucha colectiva y comunitaria más que individual; una lucha que nace del reconocimiento de la condición agencial y transformadora de los allegados.

La identificación de las dimensiones físicamaterial y comunitaria-política de la vida digna me lleva a problematizar qué significa tener el derecho a la vida digna como, en palabras del MPL, el "horizonte" político del movimiento por la vivienda. A primera vista, dicha idea operaba como un paraguas que permitía la demanda de otros derechos sociales aparte de la vivienda, como el trabajo, la salud y la educación. De allí que, como se muestra en la Figura 1, se afirmaba que la lucha de los comités de allegados "es más grande que una casa". El valor político de la noción de dignidad va, no obstante, mucho más allá de su utilización discursiva como un derecho explícitamente reivindicado por los pobres. A través de esa categoría los residentes sin casa producían narrativas mediante las cuales podrían significar políticamente sus experiencias de exclusión social. El filósofo Honneth (1992) sostiene que las ideas de integridad e irrespeto tienen una referencia implícita a la demanda de un sujeto por ser reconocido por otros. El irrespeto, por tanto, se relaciona siempre con formas de injurias que pueden incluso hacer "colapsar" (Honneth 1992:189) la identidad de una persona. Honneth identifica tres formas de irrespeto -maltrato físico, negación de derechos y degradación del valor social de individuos o grupos- los cuales son subjetivamente internalizados 
como un despojo de autoconfianza, autorespeto y autoestima. Sin embargo, la falta de reconocimiento y el sentimiento de degradación puede, advierte Honneth, transformarse en acciones de resistencia política en las que individuos y colectividades pueden reaccionar a esas formas de irrespeto. Este autor sugiere la existencia de una "pasarela semántica" (Honneth 1995:163) que media las aspiraciones impersonales de un movimiento social y las experiencias privadas de daño de sus participantes. En mi observación etnográfica, el concepto de dignidad funcionaba justamente como esta pasarela semántica. A través de ella, allegados y allegadas de Santiago podían lidiar colectivamente con distintas experiencias de injusticia, tales como la falta de viviendas sociales o el hecho mismo de ser interpelados como vulnerables por instrumentos de caracterización clasistas y discriminatorios. Como pasarela semántica, la noción de dignidad permitía, así, la articulación de un lenguaje político en que la subjetividad de los pobres urbanos establecían una relación con el yo (self) basado en "modos positivos de autoconfianza, autorespeto y autoestima" (Honneth 1992:196).

\section{Conclusiones}

En este artículo he querido demostrar cómo grupos excluidos utilizan categorías morales como la dignidad no solo, como argumentan los antropólogos de la ética ordinaria, para volverse sujetos éticos, sino también para significar políticamente sus experiencias cotidianas. Dicho proceso trae una consecuencia importante para la investigación antropológica: las categorías morales, además de verbalizar criterios de juicio prácticomediante los cuales los individuos actúan moralmente, funcionan también como indicadores que nos dejan saber cómo y bajo qué circunstancias emergen movimientos sociales que buscan transformar las vidas de las personas. Los conceptos morales como el discutido aquí son ciertamente utilizados para verbalizar acciones "a favor del bien y en contra del mal" (Fassin 2008:334). Pero, al mismo tiempo, categorías como la dignidad operan como significantes políticos por el que colectividades sufriendo alguna clase de exclusión pueden articular, configurar y dar cuerpo a las demandas por derechos, igualdad y reconocimiento.

Chile, en tanto ejemplo emblemático de gubernamentalidad neoliberal (Han 2012), es un caso importante para examinar cómo las categorías morales contribuyen a la emergencia de movimientos sociales basados en la formulación de un nuevo lenguaje de derechos. En el Chile neoliberal, la vivienda social es un bien de consumo que los pobres obtienen mediante su participación en los programas de subsidios. La mercantilización de la vivienda ha llevado a la segregación sistemática de los residentes de bajos ingresos, fenómeno que ha resultado en la aparición de nuevos reclamos por el derecho a vivir dignamente. La dignidad, entonces, se ha constituido como un concepto por el que los pobladores sin casa elaboran juicios críticos sobre sus experiencias cotidianas de allegamiento, así como sobre los modos en que son construidos como vulnerables por la Ficha de Protección Social.

Vivir en condiciones de hacinamiento y ser construidos como beneficiarios de programas sociales por instrumentos clasistas de caracterización socioeconómica son dos determinantes estructurales que mis interlocutoras significaban cotidianamente a través de lo que, siguiendo a Zigon (2007, 2014), aquí definí como colapsos morales. En esos momentos de dilemas éticos, ellas veían amenazada su identidad como sujetos dignificados, cuestión que las forzaba a desplegar ciertas tácticas reflexivas -ingresar a asambleas de vivienda o mentir en la Ficha de Protección Social- para afirmar su dignidad. A través de estas tácticas, podían superar los dilemas éticos mediante la reclamación política por derechos. De tal manera, los colapsos morales definidos por Zigon pueden dar pie a formas de resistencia colectiva una vez que éstos son entendidos como problemas políticos. Es solo entonces cuando las categorías morales usadas por los individuos se transforman en una "pasarela semántica" (Honneth 1995). Esto nos lleva a una segunda consecuencia analítica para el estudio antropológico: la noción de colapsos morales puede contribuir significativamente a las etnografías políticas interesadas en explorar de qué manera los movimientos sociales sientan las bases para que los individuos, a través de sus prácticas éticas, se constituyan como subjetividades políticas.

La comprensión de la dignidad como un derecho y como una pasarela semántica nos invita a reflexionar sobre las formas de politización que cristaliza la vida cotidiana. Para las y los habitantes sin casa, sus anhelos de surgir y salir adelante -proyectos anclados en sus deseos de ser propietarios- resultan ser profundamente políticos en la medida en que se enmarquen en sus aspiraciones por alcanzar la vida digna. Al organizar sus prácticas éticas bajo este horizonte político, ellos no solo enfrentan colectivamente los colapsos morales, sino que también se forman como sujetos ético-políticos capaces de articular un lenguaje de derechos. En ese proceso, los allegados se conciben a sí mismos como dotados de una dignidad que no les es externa; una dignidad que, consecuentemente, puede ser positivamente reivindicada como derecho cuando fuerzas estructurales amenazan su existencia como sujetos morales. Si demandan el derecho a la vida digna no es porque carezcan o hayan perdido dignidad, sino porque perciben que el sistema de desigualdad social de Chile pone en peligro su condición de sujetos dignos. Es, por tanto, la reafirmación de su dignidad como pobladores y pobladoras la condición fundamental para imaginar, dibujar y construir una vida digna. 
Agradecimientos: El autor agradece al Proyecto Anillos CONICYT PIA SOC180033 y al Centro de Estudios de Conflicto y Cohesión Social (CONICYT/
FONDAP/15130009). Además, agradece a los revisores anónimos por sus sugerencias y comentarios a la versión original del artículo.

\section{Referencias Citadas}

Angelcos, N. y M. Pérez 2017. De la ‘desaparición’ a la reemergencia: continuidades y rupturas del movimiento de pobladores en Chile. Latin American Research Review 52 (1):94-109.

Auyero, J. 2003. Contentious Lives: Two Argentine Women, Two Protests, and the Quest for Recognition. Duke University Press, Durham.

Auyero, J. 2012. Patients of the State: The Politics of Waiting in Argentina. Duke University Press, Durham.

Caldeira, T. 2015. Social movements, cultural production, and protests: São Paulo's shifting political landscape. Current Anthropology 56 (S11):S126-136.

Caldeira, T. 2017. Peripheral urbanization: autoconstruction, transversal logics, and politics in cities of the Global South. Environment and Planning D: Society and Space 35 (1):3-20.

Campero, G. 1987. Entre la Sobrevivencia y la Acción Política. Las Organizaciones de Pobladores en Santiago. Estudios ILET, Santiago de Chile.

Candia, J. 1998. Exclusión y pobreza. La focalización de las políticas sociales. Nueva Sociedad 156:116-126.

Castells, M. 1973. Movimiento de pobladores y lucha de clases en Chile. EURE 3 (7):9-36.

Castillo, M. y R. Forray 2014. La vivienda, un problema de acceso al suelo. $A R Q$ (Santiago) 86:48-57.

Cleaveland, C. 2005. A desperate means to dignity: work refusal amongst Philadelphia welfare recipients. Ethnography $6(1): 35-60$.

Cruikshank, B. 1999. The Will to Empower: Democratic Citizens and Other Subjects. Cornell University Press, Ithaca.

Das, V. 2012. Ordinary Ethics. En A Companion to Moral Anthropology, editado por D. Fassin, pp. 133-149. Wiley-Blackwell, Malden.

El Mercurio 2011. Lavín denuncia 4 mil casos que mintieron en Ficha de Protección Social. Emol. 21 de septiembre de 2011. http://www.emol.com/noticias/nacional/2011/09/21/504346/ falsos-pobres-lavin-denuncia-4-mil-casos-de-adulteracion-dela-ficha-de-proteccion-social.html.

Fassin, D. 2008. Beyond good and evil?: questioning the anthropological discomfort with morals. Anthropological Theory 8 (4):333-344.

Fassin, D. 2012. Introduction: Toward a critical moral anthropology. En A Companion to Moral Anthropology, editado por D. Fassin, pp. 1-17. Wiley-Blackwell, Malden.

Ferguson, J. 2015. Give a Man a Fish: Reflections on the New Politics of Distribution. Duke University Press, Durham.

Fisher, J. 2018. In search of dignified work: gender and the work ethic in the crucible of fair trade production. American Ethnologist 45 (1):74-86.
Han, C. 2012. Life in Debt: Times of Care and Violence in Neoliberal Chile. University of California Press, Berkeley.

Holston, J. 2008. Insurgent Citizenship: Disjunctions of Democracy and Modernity in Brazil. Princeton University Press, Princeton.

Honneth, A. 1992. Integrity and disrespect: principles of a conception of morality based on the theory of recognition. Political Theory 20 (2):187-201.

Honneth, A. 1995. The Struggle for Recognition: The Moral Grammar of Social Conflicts. Polity Press, Cambridge.

Hurtado Echeverría, C. 1957. Ante un hecho ilegal. Revista Mensaje.

Lambek, M. (ed.) 2010a. Ordinary Ethics: Anthropology, Language, and Action. Fordham University Press, New York.

Lambek, M. (ed.) 2010b. Towards an ethics of the act. En Ordinary Ethics: Anthropology, Language, and Action, pp. 3963. Fordham University Press, New York.

Larrañaga, O., D. Falck, R. Herrera y A. Telias 2014. De la ficha de protección social a la reforma de la focalización. Programa de las naciones unidas para el desarrollo-Chile. http://www. cl.undp.org/content/dam/chile/docs/pobreza/undp_cl_pobreza_ cap6_focalizacion.pdf

Margalit, A. 1996. The Decent Society. Harvard University Press, Cambridge.

Ministerio de Desarrollo Social 2014. CASEN 2013 vivienda. Síntesis de resultados. Gobierno de Chile. http://observatorio. ministeriodesarrollosocial.gob.cl/documentos/Casen2013 Situacion_Pobreza_Chile.pdf.

Movimiento de Pobladores en Lucha 2011. Siete y Cuatro. El Retorno de los Pobladores. Quimantú, Santiago de Chile.

Murphy, E. 2015. For a Proper Home: Housing Rights in the Margins of Urban Chile, 1960-2010. University of Pittsburgh Press, Pittsburgh.

Ong, A. 2003. Buddha Is Hiding: Refugees, Citizenship, the New America. University of California Press, Berkeley.

Özler, İ. 2012. The Concertación and homelessness in Chile market-based housing policies and limited popular participation. Latin American Perspectives 39 (4):53-70.

Paley, J. 2001. Marketing Democracy: Power and Social Movements in Post-Dictatorship Chile. University of California Press, Berkeley.

Pauli, J. 2008. A house of one's own: gender, migration, and residence in rural Mexico. American Ethnologist 35 (1):171187.

Pérez, M. 2017a. 'A new poblador is being born': housing struggles in a gentrified area of Santiago. Latin American Perspectives $44(3): 28-45$ 
Pérez, M. 2017b. Reframing housing struggles: right to the city and urban citizenship in Santiago, Chile. City 21 (5):530-549.

Rose, N. 1999. Powers of Freedom: Reframing Political Thought. Cambridge University Press, Cambridge.

Santa María, I. 1973. El desarrollo urbano mediante los 'asentamientos espontáneos': el caso de los 'campamentos' chilenos. EURE 3 (7):103112

Schild, V. 2000. Neo-liberalism's new gendered market citizens: the 'civilizing' dimension of social programmes in Chile. Citizenship Studies 4 (3):275-305.

Sungranyes, A. 2005. La política habitacional en Chile, 19802000: un éxito liberal para dar techo a los pobres. En Los Con Techo. Un Desafío Para la Política de Vivienda Social, editado por A. Rodríguez y A. Sungranyes, pp. 23-57. Ediciones SUR, Santiago.

Tapia, R. 2011. Vivienda social en Santiago de Chile: análisis de su comportamiento locacional, período 1980-2002. Revista INVI 26 (73):105-131.

Zeiderman, A. 2013. Living dangerously: biopolitics and urban citizenship in Bogotá, Colombia. American Ethnologist 40 (1):71-87.

Zigon, J. 2007. Moral breakdown and the ethical demand: a theoretical framework for an anthropology of moralities. Anthropological Theory 7 (2):131-150.

Zigon, J. 2014. An Ethics of dwelling and a politics of worldbuilding: A critical response to ordinary ethics. Journal of the Royal Anthropological Institute 20 (4):746-764.

\section{Notas}

${ }^{1}$ La Ficha de Protección Social fue reemplazada por el Registro Social de Hogares en 2016. Sin embargo, en este artículo analizo particularmente la primera por ser el instrumento utilizado por el Estado al momento de llevar a cabo mi trabajo de campo.

${ }^{2}$ Los nombres de las personas citadas en este artículo fueron reemplazados por seudónimos. No obstante, los nombres de organizaciones políticas, asambleas de vivienda y barrios no fueron modificados.

${ }^{3}$ Dicho fenómeno estuvo expresado en la creación de más de 1.300 organizaciones de base que, a mediados de la década de 1980, agrupaban a más de 222.000 pobladores (Campero 1987).
${ }^{4}$ Para otra aproximación antropológica al concepto de vulnerabilidad en otros contextos urbanos en América Latina, ver el trabajo de Zeiderman (2013) sobre ciudadanía y biopolítica en Bogotá.

${ }^{5}$ La escala de puntajes de la Ficha de Protección social estaba dividida en quintiles de vulnerabilidad, la que comenzaba en 2.072 puntos (la condición más vulnerable). Estos eran: Quintil I (entre 2.072 a 8.500 puntos); Quintil II (entre 8.501 y 11.734); Quintil III (entre 11.735 y 13.484); Quintil IV (entre 13.485 y 14.557); y Quintil V (sobre 14.558). Para 2015, un 54,1\% de los usuarios de la Ficha de Protección Social pertenecían al Quintil I. 